number, in oxder that its details mas be carefully examined b. the mombers of this Aseociation. In the meantime, we chenin from comments, as our object is to elicit the opinions of thow who are practically able to enlighten the profeasion and the legislature on this important question.

$\Delta$ very valuable communication on the subject of State Teccination, from the pen of Dr. Spencer Thomson, of Burton-on-Trent, will be found at p. 747 of this number.

\section{THE ROYAL MEDICAL BENEVOLENT COLLEGE ACT.}

Ar p. 749 we reprint in extenso an $\Delta$ ct of Parliament which has lately received the Royal assent, for the incorporation of the Royal Medical Benerolent College. The provision which is especially worthy of notice is that which enables other bodies throughout the country, having similar objects, to join the College. Two societies are specified by name; and the general provision is thus expressed in Section 7.

"It shall be lawful for any association or society formed exclusively or partly for the purpose of affording aid to medical men or their families, by any or either of the ways and means aforesaid, and either generally or within certain defined local limits, to transfer their funds or to subscribe money from their funds to the said College, either gratuitously for the furtherance of the general objects of the College, or any one or more of them, or upon and subject to such terns and conditions for securing special advartages to the objects (being medical men or their families) of their own immediate foundation; and shall be lawful for the College by their council, but subject to the bye-laws and rules of the College for the time being in force, to enter into such agreements with any such association or society as aforesaid, with respect to any such special advantages as aforesaid, as they may think proper, and such agreements, if confirmed by three-fifths at least of the members of the association or society party thereto, present at a meeting of such association or society specially convened for the purpose, and also if confirmed by three-fifths at least of the governors of the College present, at any extraordinary general meeting of the said governors, and by the visitor of the College, shall be binding upon the association or society party thereto, and the College."

\section{ORIGINAI COMMUNICATIONS.}

\section{ON THE THERAPEUTIC PROPERTIES OF CARBAZOTIC ACID, ETC. \\ By T. MOFFAT, M.D., F.R.A.S., etc. \\ [Read at the Annual Meeting of the North Wales Branch, July 3rd, 1855.]}

Ar the meeting of the British Association at Liverpool, in September last, Professor Crace Calvert, of the Royal Institution, Manchester, read a paper on the Physiological Properties of Carbazotic Acid. The author stated that Dr. Bell, Physician to the Royal Infirmary, Manchester, had cured several cases of intermittent fever with this acid. He also stated that he should be happy to furnish any physician with a small quantity of this substance, so that its real medical value might be ascertained. He also described the process by which pure carbazotic could be procured from carbolic acid; and impressed upon the meeting the value of the pure acid as a yellow dye for silk.

Through a mutual friend, Professor Crace Calvert sent me a supply of carbazotic acid, carbazotate of ammonia, and carbazotate of potassa. I prescribed the articles in several cases; and it is with his leave that I bring the rewilt of my experience before this meeting.

I may here state, that carbazotic acid was discovered by
Theltar, and is comotimes called Weltar's bittore. It has been chicty studied by Gay Inesac, Cherreul, Piria, and Dumas. It is formed by the action of nitric acid on indigo, aloes, silk, and other organic subetances. It forms jellow shining scales, soluble in water, to which it gires an intense yellow colour and bitter taste. The process recommended by Liebig for preparing it consists in boiling ten parts of diluted nitric acid on one of indigo, and adding to the liquid, when cold, a quantity of potassa. The potassa combines with the carbazotic acid, and forms carbazotate of potassa; which, in its turn, is decomposed by the addition of another acid, by which the carbazotic is set at liberty, and is deposited in brilliant yellow crystals. It is soluble in alcohol and ether. It unites with salifiable bases, and forms compound salts. The name is derived from its composition, which, according to Liebig, consists of

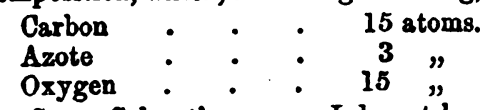

Professor Crace Calvert's process I do not know; but, as I have before stated, the carbazotic is procured from carbolic acid, which, you are no doubt aware, is one of the products obtained in the distillation of coal tar.

Carbazotic acid, prepared according to the process of Pro. fessor Crace Calvert, I am informed, is a much cheaper* and a better article than that procured from indigo.

In a therapeutic sense, carbazotic acid and the carbazotates may be ranked with the tonic and astringent classes of remedies; but their astringent qualities, I believe, act indirectly; $i . e$, they restrain discharges, by improving the general tone of the system. I have prescribed the remedies in the following cases.

The first case in which I used the carbazotic acid was that of a woman suffering from an attack of continued fever, complicated with subacute peritonitis and tympanitis. When the case had progressed to that stage in which the use of tonics and stimulants is indicated, I prescribed grain doses of the remedy three times a day. The woman got well just as if quinine had been administered.

The next case was that of a woman suffering from anæmia. She was recovering under the use of quinine and iron. I suspended the quinine and chalybeate treatment, and gave carbazotate of ammonia, in grain doses, three times a day. She lost ground while taking the carbazotate, and again improved on resuming the quinine and chalybeate remedies.

The next was that of a child ill of scarlatina maligna. Carbazotic acid and wine were administered. The child died.

I prescribed it next in a case of chronic eczema; and the patient got well.

Believing that carbazotic acid, in combination with ammonia and potassa, possessed tonic qualities, I felt inclined to try it in combination with metallic bases; and, at my suggestion, Professor Calvert prepared some carbazotate of iron and carbazotate of zinc. At the time I received them, I had two cases of cephalalgia under my care. One was of long standing. In one, I gave grain doses of carbazotate of zinc; and in the other (that of long standing), I prescribed the same quantity of carbazotate of iron three times a day, in combination with extract of conium. The carbazotate of zinc produced nausea and other unpleasant feelings; and the woman said I had poisoned her. I stopped the carbazotate of zinc, and gave carbazotate of iron, as in the other case. This did not produce any unpleasant effects. Both cases improved : indeed, one case got quite well; and that of long standing got so much better that I have not been called upon to prescribe for it since, and a month or more has elapsed since the remedy was administered. The quantity taken by each patient was thirty-two grains, in a period of fourteen days. In both cases, quinine and iron were tried, in combination with the same extract; and, in the case of long standing, sulphate of zinc and strychnine were taken without relief.

- Carbazotic actd, by this proceas, as I hear, can be propared for about 6s. to 6s. per pound. 
I shell.now reed notes of two cases in which the carber Itato of ammonis was eminently successful.

CABE 1. 8. E., aged 17 jears, had lately sufiered from an attack of continued fever. Diarrhos continued during his convalescence, and for some time after he had so far recovered as to be able to walk about. On the 21st of May last, I prescribed grain doses of carbazotate of ammonia and gallic acid, with one sixth of a grain of opium, three times a day. On the 26th, i. e., five days afterwands, I saw him again; and he had improved. On the 2nd of June, the him again ; and he had, and continued daily. On the 7 th, I reported him cured.

This young man had not been free from diarrhoea for three months previous to his taking the above medicines; and, during that period, gallic acid, acetate of lead, and opium, were administered without effect. He is now quite well.

Case Ir. The next case was one of diarrhcea, of eighteen months' standing. The patient was suffering from menthe 4th of June, he began the same remedies, in similar quantities as June, he began the preceding case. I lost sight of this patient for a time. I saw him, however, five days ago; and he said that he did not return, as the "bowel complaint was quite gono". Acetate of lead and opium had been administered in this case also without any good result. The sycosis is no better.

There is a circumstance in connexion with this subject of much physiological interest; and I feel that I shall not hare performed my part if $I$ do not bring it under your notice.

I have prescribed carbazotic acid and the carbazotates of potassa, ammonia, iron, and zinc, in eight cases; and, in four of these, the skin and conjunctiva became yellow during the administration of the remedies. They were completely jaundiced; and I believe that the yellowness was owing to the colouring matter of the remedies having tinged the serum of the blood. The coloration may have been owing to some change produced in the biliary system by the remedies; but I am inclined to the former opinion. The tinge of the skin and conjunctiva so perfectly resembles jaundice, that the keenest observer would be deceived; and I believe that, if the fact were generally known, there would be jaundiced impostors and malingerers without end.

In conclusion, I beg to remind you that Professor Crace Calvert will be most happy to supply any of you with small quantities of the articles, provided you will let him have the result of your experience. Your reports may be sent direct to him, or through me; and I shall be very glad to be the means of supplying any of you with the articles, and forwarding any reports you may favour me with. I beg to express a hope that some of you will try the remedies; for when we consider that, as has been before stated, Dr. Bell has cured several cases of ague with the carbazotic acid, and that the carbazotates appear to possess tonic qualities equal to quinine (one ounce of which is double the price of one pound of the other articles), their introduction into hospital and union practice is of paramount importance.

Hawarden, July 1855.

I

\section{CASE OF POISONING BY CHLORIDE OF ZINC.}

By GEORGE WILLIS, M.D.

Mr. P., on the 29th April, at 1 P.M., swallowed by mistake about an ounce of Crews' disinfecting liquid : this is, I believe, a saturated solution of chloride of zinc. On my arrival, five minutes after the accident, I found Mr. P. vomiting, having previously swallowed a large quantity of water. The matter then rejected had to me no very styptic taite. I thought it desirable to promote the vomiting, and gave large draughts of warm water and of infusion of blect to The patient was then complaining of great pain and heat in the stomach and bowels.

In the course of half an hour, he pessed a large loose and watery motion; after that he wont to bed, and had and watery motion; after that pain, and gum-water for drink, with pounded ice in it.

In the evening, desire to go to stool was accompanied for two hours by the discharge of nearly three pints of mucus mixed apparently with shreds of the intestinal mucous membrane. There was not abdominal tendernees, a hard jerking pulse, constant nausea, and occasional romiting.

At 10 P.M., I applied six leeches to the abdomen, and promoted the bleeding by hot poultices. Two hours afterwards, the patient fell into a tranquil sleep, which lasted throughout the night.

During the ensuing fire days, the treatment consisted in giving very little food, and that liquid and cold; the most distressing symptom was flatulency; this was greatly relieved by mixing lime-water with his milk diet. I should lieved by mixing lime-water with and fauces had escaped injury; Mr. P. having, what is vulgarly called, "bolted" the dose, thinking it to be fluid magnesia. By this time the abdominal tenderness had passed away; the pulse had lost much of its jerking feel; the bowels had acted the lost much of its jerking after the accident; the stool was mixed with mucus, and deficient in bile. The fact of his being the subject of chronic hepatic disease made this symptom appear of little importance.

May 5th. The case to day suddenly assumed a less favourable aspect. He complained of a throbbing in every part; the tongue was dry, red, and glazed; the pulse part; the tongue to-day three clay-coloured motions, the quick, he passed a tape-like appearance. He was ordered to take a pill of hydrargyrum cum creta, with extract of to take a pill of hydrargyrum cuming draught, containing liquor ammoniæ acetatis and spirits of nitric æther, every four hours.

May 7th. The tongue was moist, but very red; the secretions from the bowels more natural; spirits good. The patient, on his part, declared himself well, and asked to discontinue his medicine, and have animal food for dinner.

May 8th. This morning he felt sick, and rejected a quantity of dark coloured thick fluid from the stomach; he also passed a little tar-like matter from the bowels. I ordered a turpentine mixture, and pills containing acetate of lead and creasote, every three hours.

May 9th. He felt quite comfortable, and in excellent spirits; all his symptoms appeared alleviated.

May 10th. I was called up early to find my patient much worse. He had had no sleep all night, and was suffering from nausea; his belly was distended, his counfering from nausea, ha his pulse was small and quick. While at the night-chair passing a large quantity of melena, he romited three pints of black fluid blood, and was carried fainting into bed, where he died in three hours from that time. At the post mortem examination, made forty-eight hours afterwards, I found the abdomen tense and distended with gas, but no trace of peritoneal inflammation. There was cirrhosis of the liver from the previous habits of life. The pyloric end of the stomach was 80 soft as to be torn through in its removal, and the stomach and small intestines were full of blood. Large patches of ulceration were found in the stomach and small intestines.

Cases of poisoning with chloride of zinc are rare. One instance, in which a child was nearly killed by drinking some of Crews' liquid, is recorded in the Associarion JodRNAL for November 24th, 1854,

Monmonth, July 29th, 1855. 